\title{
H eterocontrole da fluoretação da água de abastecimento público de Lages, Santa Catarina, Brasil
}

\author{
External control of fluoride levels in the public water supply \\ in Lages, Santa Catarina State, Brazil
}

Ramona Fernanda Ceriotti Toassi ${ }^{1}$

M irian Kuhnen ${ }^{1}$

Gisela Ana Cislaghi ${ }^{1}$

Jocelito Rosa Bernardo ${ }^{1}$

${ }^{1}$ Departamento deCiências

Abstract The purpose of this study is a monthly assessment of fluoride levels in the public water supply in Lages, Santa Catarina State, Brazil. This town was divided into ten regions, where water samples were collected from 0 ctober 2004 to September 2005. Two samples were drawn from each region and sent to the Fluoride $\mathrm{H}$ ealth Surveillance Laboratory at Vale do I tajaí University for analysis through an electrometric method (Orion 920A/Orion Electrode 9609). After twelve months, 120 samples had been collected, demonstrating gapsin thefluoridelevelsand somepoints with excessive fluoride levels (35,8\%). Several points with ideal fluoride concentrations ( $54.2 \%$ ) also appeared. These findings lead to the conclusion that external controls are required for monitoring fluoride levels in the public water supply in Lages.

Key words Fluoridation, Water treatment, Water analysis, Water supply
Biológicas eda Saúde,

Faculdade deO dontologia,

UNIPLAC. Av. Castelo

Branco 170, Universitário.

88509-900 Lages SC.

ramona@uniplac.net
Resumo 0 objetivo deste estudo foi monitorar mensalmente e oficializar um programa de heterocontroledosníveis de flúor na água deabastecimento público de Lages, Santa Catarina, Brasil. 0 município foi dividido geograficamente em dez pontos e a coleta realizada de outubro de 2004 a setembro de 2005, em duplicata. Após a coleta, as amostras eram enviadas para o Laboratório de Vigilância Sanitária de Flúor da Universidade do Vale do Itajaí (Santa Catarina), que realizou asanálises utilizando o método eletrométrico (O rion 920A/Eletrodo O rion 9609). A pós doze meses, 45,8\% das amostras deágua col etadas apresentaram teoresinadequados deflúor. Verificou-seuma elevada e contínua variabilidade nos resultados. Entre os pontos que apresentaram teores inadequados de flúor, houve predomínio daqueles com excesso de fluoretos (35,8\%). Também houve um significativo número de unidades amostrais com uma concentração adequada deflúor (54,2\% ). Os resultados permitiram concluir que o heterocontroleem Lages éfundamental para a manutenção de um correto programa de fluoretação das águas de abastecimento público.

Palavras-chave Fluoretação, Tratamento da água, Análise da água, Abastecimento deágua 


\section{Introdução}

A fluoretação das águas de abastecimento éconsiderada uma medida coletiva de aplicação de flúor maisimportante em Saúde Pública, por ser o método mais eficiente, adequado, prático, econômico e perene de prevenção da cárie dentária, desde que respeitadas a continuidade e regularidade dos teores adequados ${ }^{1,2,3}$.

Programas de fluoretação da água têm sido implementados em aproximadamente 39 países, atingindo mais de 200 milhões de pessoas. Acrescenta-se a isto um adicional estimado de outras 40 milhões de pessoas que ingerem água naturalmente fluoretada 4 .

Estudos científicos observaram sua ação na diminuição da prevalência da cárie dentária de 40 a $60 \%$, quando comparada com as regiões não-fluoretadas ${ }^{5}$. N ewbrun ${ }^{6}$, Cury ${ }^{7}$, Cury $^{8}$ ePinto ${ }^{9}$ relataram que comunidades que consomem água fluoretada em níveis ideais, sem interrupções, têm conseguido reduzir os níveis de cárie em 50 a $60 \%$.

A primeira cidade do mundo a implantar um sistema de fluoretação de águas foi o município de Grand Rapids, nos Estados Unidos, em 1945, produzindo reflexos positivos tanto na saúde pública quanto na prática odontológica ${ }^{1}$.

Recomendada pela Associação Dentária Americana desde 1950 e pela Organização M undial da Saúde (OMS) desde 1969, a fluoretação deáguas no Brasil vem sen do utilizada desde 1953, como primeiro projeto instalado em Baixo Guandu, no Espírito Santo ${ }^{10,11}$. Além disso, o Brasil determina a obrigatoriedade da implantação do método por meio da Lei 6.050 edo Decreto 76.872 de $1975^{12}$.

A pesar de todas as vantagens comprovadas que a fluoretação de águas pode proporcionar como medida de promoção de saúde e prevenção da cárie dentária, muitas são as cidades brasileiras que não dispõem desse processo ou não possuem uma política de vigilância sanitária que controle de forma satisfatória a sua execução ${ }^{13}$. Contudo, para que esta medida possa efetivamente oferecer os benefícios esperados, é necessário que seja mantida a continuidade eregularidade dos teores ótimos de íon flúor presentes nas águas de abastecimento ${ }^{2}$. A pesar de todas as vantagens e benefício comprovados que o flúor pode proporcionar, como qualquer outra substância farmacologicamente ativa, deve ter sua utilização controlada em termos derisco-ben efício, uma vez que, enquanto a subdosagem não traz ben efícios, a sobredosagem, por tempo continuado, durante o período de formação dos dentes, associa-seà ocorrência de uma anomalia de desenvolvimento que afeta a estética do esmalte dos dentes sob a forma de manchas conhecidas como fluorose dentária $a^{3,14}$.
No Brasil, estima-se que aproximadamente 65 milhões de brasileiros ingiram água fluoretada em quase mil municípiost. Em Santa Catarina, 130 dos 217 municípios, em junho de 1992, eram beneficiados por esta medida de Saúde Pública ${ }^{15}$. Em um estudo feito em 25 estados do Brasil, observou-sequeum percentual muito al to das 8.032 amostras analisadas apresentavam concentrações deflúor inadequadas. Segundo Ferreira ${ }^{15}$, em Santa Catarina, $48,71 \%$ da água tratada apresentaram níveis deflúor insuficientes, 35,64\% apresentaram níveis adequados e $15,64 \%$ tinham excesso deflúor. A concentração média de flúor das 1010 amostras de água tratada foi de 0,652 partes por milhão (ppm), sugerindo que o Estado precisaria consumir mais água, para que a população recebesse água adequadamente fluoretada.

Em Lages, estudo realizado por Ferreira ${ }^{15}$ nos anos de 1994, 1995 e 1996 mostrou que, das 50 amostras deáguas tratadas analisadas, $36 \%$ apresentavam teores insuficientes de flúor e $64 \%$, teores adequados de flúor na água de consumo.

Em 2003, porém, uma pesquisa sobre prevalência de cárie dentária na Escola Lupércio de Oliveira Köeche, situada no bairro da Várzea, em Lages, que também contemplava a vigilância sanitária dos teores de flúor da áqua consumida por esta população escolar, mostrou que, das 35 amostras de água analisadas de agosto de 2003 a fevereiro de 2004, todas apresentaram teoresinadequados de flúor para o município de Lages, sendo que 34 apresentaram valores insuficientes deflúor e 1 apresentou excesso de flúor ainda no primeiro mês de coleta. Já nos meses de abril e maio de 2004, alguns poucos pontos passaram a apresentar teores adequados de flúor na água, sempre de modo irregular (Tabela 1).

Diante deste quadro e com o objetivo de suprir a carência deinformações, o presenteestudo preten de vigiar, de forma periódica e sistemática, o teor de flúor adicionado à água de abastecimento público de Lages - SC, já que não fluoretar a água no Brasil ou interromper sua continuidadeéconsiderada uma atitude juridicamenteilegal, cientificamenteinsustentável esocialmente injusta.

\section{Métodos}

0 município de Lages situa-se no Planalto Serrano, no centro do Estado de Santa Catarina e possui uma população de $\mathbf{1 5 7 . 6 8 2}$ habitantes. Sua zona urbana apresenta 153.582 habitantes ${ }^{16}$. 0 abastecimento público deágua do município atinge a maior parte da população da zona urbana (99\%). o órgão responsável pelo tratamento da água de abastecimento público do município é a Secretaria Municipal de Água e Saneamento (SEM ASA). 
Tabela 1. Resultados das análises de flúor da água de abastecimento público do bairro da Várzea, Lages, SC, Brasil, agosto de 2003 a maio de 2004*.

\begin{tabular}{|c|c|c|c|c|c|c|c|c|c|}
\hline $\begin{array}{l}\text { Pontos de } \\
\text { coleta de } \\
\text { água }\end{array}$ & $\begin{array}{c}\text { Mês } \\
8 / 2003\end{array}$ & $\begin{array}{c}\text { Mês } \\
9 / 2003\end{array}$ & $\begin{array}{c}\text { Mês } \\
10 / 2003\end{array}$ & $\begin{array}{c}\text { Mês } \\
11 / 2003\end{array}$ & $\begin{array}{c}\text { Mês } \\
12 / 2003\end{array}$ & $\begin{array}{c}\text { Mês } \\
1 / 2004\end{array}$ & $\begin{array}{r}\text { Mês } \\
2 / 2004\end{array}$ & $\begin{array}{c}\text { Mês } \\
4 / 2004\end{array}$ & $\begin{array}{c}\text { Mês } \\
5 / 2004\end{array}$ \\
\hline Ponto 1 & 0,43 & 0,36 & 0,38 & 0,42 & 0,41 & 0,48 & 0,33 & 0,69 & 0,51 \\
\hline Ponto 2 & 1,04 & 0,44 & 0,41 & 0,39 & 0,16 & 0,49 & 0,34 & 0,79 & 0,65 \\
\hline Ponto 3 & 0,15 & 0,36 & 0,41 & 0,55 & 0,32 & 0,54 & 0,41 & 0,70 & 0,63 \\
\hline Ponto 4 & 0,46 & 0,44 & 0,40 & 0,62 & 0,15 & 0,50 & 0,33 & 0,56 & 0,50 \\
\hline Ponto 5 & 0,43 & 0,44 & 0,38 & 0,44 & 0,40 & 0,54 & 0,30 & 0,60 & 0,73 \\
\hline
\end{tabular}

Valores de referência: de 0,7 a 1,0 ppmF.

* No mês de março de 2004, a análise da água não foi realizada.

A água de abastecimento público de todo município de Lages passou a ser analisada quanto aos seus teores de flúor a partir do mês de outubro de 2004. 0 mês de setembro, data de início da pesquisa, serviu para o estabelecimento dos pontos de coleta de água e contato com autoridades, moradores eórgãos públicos envolvidos.

O laboratório de referência para as análises foi o Laboratório deV igilância Sanitária deFlúor - Faculdade de Odontologia do Vale do Itajaí FAOVI/UN IVALI, em Itajaí, Santa Catarina.

O mapeamento dos pontos de coleta levou em consideração o número de habitantes abasteci dos pela água tratada (cidades com 100 a 200 mil habitantes, como éo caso de Lages, no mínimo dez pontos de coleta) ${ }^{15}$.

A coleta foi realizada mensalmente, em um único dia, em dias previamente sorteados, em duplicata, ao longo dos dez meses de duração oficial da pesquisa. As amostras foram coletadas em dois frascos plásticos de $5 \mathrm{ml}$, para cada ponto de coleta. Antes da coleta, os frascos eram enxaguados por três vezes com a mesma água e ser coletada e identificados. Fez-se uma lista com o endereço completo dos pontos de coleta, o dia, a hora e o responsável pela mesma. Os pontos de coleta foram divididos geograficamente de maneira que abrangesse todas as regiões da cidade e estavam situados em locais públicose diretamente de torneiras ligadas à rede de abastecimento.

O envio ao Laboratório de Vigilância Sanitária do Flúor da UNIVALI foi feito, preferencialmente, no mesmo dia da coleta. A mensuração dos níveis de flúor na água aconteceu no máximo quinze dias após a coleta, para não haver alteração dos resultados, já que não há variação dos mesmos quando fechados em frascos plásticos num período de até 150 dias $^{17}$.

Para a determinação da concentração deflúor na água, foi utilizado o método eletrométrico descrito por Frant e Ross ${ }^{18}$, que se baseia na medida direta dosíons fluoretos livres. Um eletrodo combinado seletivo para flúor (Orion 9609BN) é utilizado em conjunção com o medidor de atividade iônica (Orion 920A). O elemento chave do eletrodo é uma membrana de cristal que separa uma solução interna de fluoreto da água na qual se submerge 0 eletrodo. Como resultado das diferentes concentrações de flúor, se estabelece uma diferença de potencial em "volts" por meio da membrana. 0 el etrodo é calibrado com soluções de fluoreto de sódio em concentrações conhecidas. Para que as soluções padrões e as amostras sejam de forças iônicas comparáveis, foi adicionado às soluções um tampão ajustador de força iônica com CDTA (Ácido Ciclo-Hexano Diamino Tetracético), o qual promove reação de complexação dos íons interferentes, evitando a reação desses com o íon fluoreto. Para a obtenção de resultados mais precisos, as concentrações das amostras sempre estiveram entre os limites máximo e mínimo da curva de padrões ${ }^{15}$. Embora o método eletrométrico exija o equipamento mais caro, o procedimento é muito simples; devido à seletividade do eletrodo quando usado em presença do tampão ajustador deforçaiônica, raramenteénecessário a destilação preliminar. É considerado o método mais exato quando comparado com o visual de alizarina e com o SPAD NS fotométrico ${ }^{19}$.

A concentração deflúor aceitável identificada nas amostras e medida por parte por milhão (ppm) foi definida a partir das médias máximas diárias da temperatura do ar. No caso de Lages, a média das temperaturas máximas diárias verificadas até o mês de julho de 2005 foi de 21,55 $\mathrm{C}^{20}$. Estabeleceu-se, então, valores de níveis de flúor adequados na faixa de 0,7 a 1,0 ppm, sendo 0,8 o teor considerado ideal para a água de abastecimento público. 


\section{Resultados}

As concentrações de íons flúor obtidas das análises laboratoriais das amostras de água coletadas realizadas por laboratório independente variaram entre 0,24 e 1,63 ppmF. Os dados são apresentados nas Tabelas 2 e 3.

Nesses doze meses de coleta, pode-se observar que $45,8 \%$ das 120 amostras de água coletadas apresentaram teores inadequados de flúor na água de Lages, sendo $10 \%$ com teores insuficien- tes de flúor (abaixo de 0,7 ppmF) e 35,8\% com teores excessivos de flúor (acima de 1,0 ppmF).

No mês de novembro de 2004, os teores de flúor estavam adequados em todos os pontos de coleta analisados. Já o mês de maio de 2005 caracterizou-se pela presença de excesso de flúor em todos os pontos de coleta.

As maiores irregularidades foram observadas nos meses de fevereiro a junho de 2005, predominando pontos com excesso de fluoretos. Destaca-sequeno mês demarço de2005, ao con-

Tabela 2. Resultados das análises de flúor da água de abastecimento público, Lages, SC, Brasil, outubro a dezembro de 2004.

\begin{tabular}{llll}
\hline Pontos de coleta de água & Mês 10/2004 & Mês 11/2004 & Mês 12/2004 \\
\hline Ponto 1: Bairro Santa M ônica & 0,93 & 0,85 & 0,71 \\
Ponto 2: Bairro Nossa Senhora Aparecida & $\mathbf{0 , 6 5}$ & 0,89 & 0,79 \\
Ponto 3: Bairro Santa Catarina & 0,96 & 0,92 & $\mathbf{0 , 6 2}$ \\
Ponto 4: Bairro Centro & 0,91 & 0,81 & 0,86 \\
Ponto 5: Bairro Sagrado Coração de Jesus & 0,93 & 0,86 & $\mathbf{0 , 6 1}$ \\
Ponto 6: Bairro M aria Luíza & $\mathbf{1 , 0 8}$ & 1,00 & $\mathbf{1 , 0 2}$ \\
Ponto 7: Bairro Araucária & $\mathbf{0 , 6 8}$ & 0,70 & 0,79 \\
Ponto 8: Bairro Universitário & 0,95 & 0,90 & 0,81 \\
Ponto 9: Bairro Coral & $\mathbf{1 , 1 2}$ & 0,99 & 0,91 \\
Ponto 10: Bairro Gethal & $\mathbf{1 , 1 4}$ & 0,95 & 0,74
\end{tabular}

Valores dereferência: de 0,7 a 1,0 ppmF.

Tabela 3. Resultados das análises de flúor da água de abastecimento público, Lages, SC, Brasil, janeiro a setembro de 2005.

\begin{tabular}{|c|c|c|c|c|c|c|c|c|c|}
\hline Pontos de coleta de água & $\begin{array}{c}\text { Mês } \\
1 / \\
2005\end{array}$ & $\begin{array}{c}\text { M ês } \\
2 / \\
2005\end{array}$ & $\begin{array}{c}\text { Mês } \\
03 / \\
2005\end{array}$ & $\begin{array}{c}\text { Mês } \\
04 / \\
2005\end{array}$ & $\begin{array}{c}\text { M ês } \\
05 / \\
2005\end{array}$ & $\begin{array}{c}\text { Mês } \\
06 / \\
2005\end{array}$ & $\begin{array}{r}\text { Mês } \\
07 / \\
2005\end{array}$ & $\begin{array}{c}\text { Mês } \\
08 / \\
2005\end{array}$ & $\begin{array}{c}\text { M ês } \\
09 / \\
2005\end{array}$ \\
\hline Ponto 1: Bairro Santa M ônica & 0,74 & 0,95 & 0,92 & 0,98 & 0,54 & 0,74 & 0,66 & 0,97 & 1,21 \\
\hline Ponto 2: Bairro N. Senhora Aparecida & 0,82 & 1,08 & 0,83 & 0,88 & 1,14 & 0,86 & 0,76 & 0,91 & 1,27 \\
\hline Ponto 3: Bairro Santa Catarina & 0,73 & 0,90 & 0,40 & 0,82 & 1,33 & 1,01 & 0,83 & 1,05 & 1,05 \\
\hline Ponto 4: Bairro Centro & 0,73 & 0,91 & 1,34 & 1,25 & 1,38 & 1,29 & 0,95 & 1,05 & 1,05 \\
\hline Ponto 5: Bairro Sagrado Coração de Jesus & 0,82 & 1,13 & 0,76 & 1,21 & 1,42 & 1,21 & 0,95 & 0,90 & 0,90 \\
\hline Ponto 6: Bairro M aria Luíza & 0,99 & 1,04 & 0,55 & 1,14 & 1,63 & 1,32 & 1,07 & 0,85 & 0,85 \\
\hline Ponto 7: Bairro Araucária & 0,91 & 1,20 & 0,32 & 0,93 & 1,45 & 1,44 & 1,00 & 0,87 & 0,87 \\
\hline Ponto 8: Bairro Universitário & 0,99 & 1,17 & 0,24 & 1,40 & 1,54 & 1,23 & 0,96 & 0,87 & 0,87 \\
\hline Ponto 9: Bairro Coral & 0,97 & 1,26 & 0,64 & 0,93 & 1,47 & 1,29 & 1,20 & 0,89 & 0,89 \\
\hline Ponto 10: Bairro Gethal & 1,04 & 1,30 & 0,79 & 1,23 & 1,55 & 1,19 & 0,64 & 0,90 & 0,90 \\
\hline
\end{tabular}

Valores de referência: de 0,7 a 1,0 ppmF. 
trário do de vinha acontecendo nos meses anteriores, $50 \%$ dos pontos de coleta estavam com teores insuficientes de flúor. No mês de maio apenas um ponto e, em julho, dois pontos apresentaram teores insuficientes de flúor.

N os meses de janeiro, fevereiro, abril, agosto e setembro de 2005 nenhum ponto estava com teores insuficientes de flúor, mas 1 (janeiro), 7 (fevereiro), 5 (abril), 9 (maio), 8 (julho), 2 (agosto) e 4 ( setembro) estavam com excesso, o que também deve ser observado com cautela.

\section{Discussão}

Ao longo dos anos, a odontologia tem passado por grandes mudanças relacionadas ao entendimento do processo saúde-doença, assumindo novas posturas preventivas em relação à doença cárie. N as últimas décadas do século XX, a medida de maior impacto referente ao controle do desenvolvimento dessa doença foi o uso de flúor. Em relação à utilização do flúor em saúde pública, de acordo com dados da Organização Mundial de Saúde, a fluoretação das águas de abastecimento público tem sido uma das principais medidas na redução dos índices de cárie em todo 0 mundo ${ }^{13}$. A fluoretação da água de abastecimento público é considerada o método coletivo mais eficaz de prevenção da cárie, de melhor relação custo-benefício, por ser capaz de atingir todos os segmentos da população, independentemente da idade e do nível socioeconômico ou cultural ${ }^{21}$.

Segundo Nadanovsky²2, a redução mundial da doença cárie pode ser explicada por diversos motivos, tais como os dentifrícios com flúor, mudanças no consumo de açúcar, mudanças no diagnóstico da cárie e também pela fluoretação das águas de abastecimento público. Porém, como a maioria das ações de saúde pública, desde a sua implantação, a fluoretação tem enfrentado grupos opositores e fal has na continuidade do método que, indiscutivelmente, só terá efetividade se os níveis de flúor estiverem dentro do considerado "nível ótimo" e de forma ininterrupta por longos períodos².

Silva ${ }^{23}$ observou que a descontinuação da fluoretação da água de abastecimento público, via de regra, resulta em um aumento no índice de cárie da população.

Em Lages, os resultados de um ano de heterocontrole mostraram uma irregularidade de teores de flúor em quase $50 \%$ dos pontos analisados. Destes pontosirregulares, a maioria ( $78,2 \%$ ) apresentou teores excessivos de flúor.

Barros et al. ${ }^{24}$ mostraram a inadequação dos teores deflúor na água de abastecimento público de Porto Alegre, Rio Grande do Sul, num período de análise de treze anos, o que confirma a importância do heterocontrole na busca da manutenção de um correto programa de fluoretação deáguas. Lima et al. ${ }^{2}$, no município de Pelotas, Rio Grande do Sul, também verificaram uma inconstância nos resultados de dozemeses deheterocontrole.

\section{Conclusões}

Apesar do pouco tempo demonitoramento, após doze meses de análise dos teores deflúor da água, observa-se que o heterocontrole é essencial em Lages, uma vez que os níveis de flúor na água apresentaram elevada e contínua variabilidade, prejudicando o efeito preventivo da fluoretação no controle da cárie dentária e aumentando os riscos de fluorose. Sugere-se a continuação do heterocontrole enquanto houver fluoretação das águas de abastecimento público em Lages.

\section{Colaboradores}

RFC Toassi trabalhou na concepção, redação final e aprovação da versão a ser publicada. M Kuhnen e GA Cislaghi trabalharam na metodologia e JR Bernardo, na pesquisa e redação dos resultados. 


\section{Referências}

1. Horowitz HS. The effectiveness of community water fluoridation in the United States. Journal Public Health Dentistry 1996; 56:253-58.

2. Lima FG, Lund RG, Justino LM, Demarco FF, Del Pino $F A B$, Ferreira $R$. Vinte e quatro meses de heterocontrole da fluoretação das águas de abastecimento público de Pelotas, Rio Grande do Sul, Brasil. Cad Saúde Pública 2004; 20(2): 422-29.

3. Aerts $D, A$ begg $C, C$ esa, K. $O$ papel do cirurgiãodentista no Sistema Único de Saúde. Rev C S Col 2004; 9(1):131-38.

4. Ministério da Saúde. Parecer técnico de 24 de agosto de 1999, do Comitê Técnico - Científico (CTC) de assessoramento à área técnica de saúde bucal do Ministério da Saúde, DF, Brasil, com o objetivo de esclarecer seu posicionamento técnico-científico sobre o método de fluoretação da água de abastecimento público. Brasília: Ministério da Saúde; 1999.

5. Dantas NL, Domingues JEG. Sistema de Vigilância dos Teores de Flúor na Água de Abastecimento Público de Curitiba. Divulgação em Saúde para De bate 1996, 13:70-82.

6. Newbrun E. Cariologia. $2^{\mathrm{a}}$ ed. São Paulo: Santos; 1988.

7. Cury JA. Uso do Flúor. In: Baratieri LN, et al. Procedimentos preventivos e restauradores. São Paulo: Santos; 1989. p. 60.

8. Cury JA. Fluoretação da água: benefícios, riscos e sugestões. Revista O dontológica do Brasil Central 1992; 2(5):32-4.

9. Pinto VG. Saúde bucal coletiva. $4^{\text {a }}$ ed. São Paulo: Santos; 2000. p.158-73.

10. Torriani DD. Cárie dental: métodos preventivos. In: Busato AL, et al. Dentística: restaurações em dentes posteriores. São Paulo: Artes M édicas; 1996. p. 12-22.

11. Ferreira HCG, Gomes AMM , Silva KRCS, Rodrigues CRM D, Gomes AA. Avaliação do teor de flúor na água de abastecimento do município de Vitória - ES. Revista APCD 1999; 53(6):455-59.

12. Lei federal 6.050 de 24 de Maio de 1975. Decreto federal 76. 872 de 22 de Dezembro de 1975. Dispõe sobre a fluoretação da água em sistemas de abastecimento público quando existe estação de tratamento. Diário Oficial da União 1975.
13. Maia LC, Valença AM G, Soares EL, Cury JA. Controle operacional da fluoretação da água de $\mathrm{Nite}$ rói, Rio de Janeiro, Brasil. Cad Saúde Pública 2003; 19(1):61-7.

14. Toassi RFC, Abegg C. Fluorose dentária em escolares de um município da serra gaúcha, Rio Grande do Sul, Brasil. Cad Saúde Pública 2005; 21(2):652-55.

15. Ferreira R. Fluoretação das águas de abastecimento público no Estado de Santa Catarina nos anos de 1994, 1995 e 1996. II Encontro Catarinense de Odontologia em Saúde Coletiva 1996:36-41.

16. Instituto Brasileiro de Geografia e Estatística (Ibge). Censo Demográfico 2000. Disponível em: http:// www1.ibge.gov.br/cidadesat/default.php

17. Prado IAT, Beevmlieri CM, Narvai, PC, Scheneider, DA, M andrefini, MA. Estabilidade do flúor em amostras de água. RGO 1992; 40: 197-99.

18. Frant M, Ross JR, James W. Electrode for sensing fluoride ion activity in solution. Science 1966; 154:1553-54

19. Schneider Filho DA, Prado, IT, Narvai, PC, Barbosa, SE. Fluoretação da água. Como fazer a vigilância sanitária? Cadernos de Saúde Bucal 1992; 1:1-23.

20. Empresa de Pesquisa Agropecuária e Extensão Rural de Santa Catarina (Epagri). Boletim das temperaturas diárias médias de Lages - SC. Florianópolis; 2005.

21. Brandão IM GB, Valsecki Junior A. Análise da concentração de flúor em águas minerais na região de Araraquara, Brasil. Revista Pan Americana de la SaIud/Pan American Journal Public Health 1998; 4(4):238-42.

22. Nadanovsky P. 0 declínio da cárie. In: Pinto VG. Saúde bucal coletiva. $4^{a}$ ed. São Paulo: Santos; 2000. p. 341-51.

23. Silva MFA. Prevenção da cárie dental. In: Pinto VG. Saúde bucal coletiva. $4^{\mathrm{a}}$ ed. São Paulo: Santos; 2000. p. 353-401.

24. Barros ERC, Tovo M F, Scapini C. Análise crítica da fluoretação de águas no Município de Porto Alegre/RS. RGO 1990; 38:247-54.

Artigo apresentado em 10/01/2006

Aprovado em 05/09/2006

Versão final apresentada em 16/01/2006 